\title{
AC 2009-583: DESIGN EDUCATION AT CAL POLY: WHY WE DO WHAT WE DO
}

\section{Saeed Niku, California Polytechnic State University}

Saeed Niku is a professor of mechanical engineering at Cal Poly, San Luis Obispo. He has taught courses in mechanics, robotics, and design since 1983. His research interests are in the same areas, as well as biomechanics and design for the disabled. He has also written two textbooks, "Introduction to Robotics; Analysis, Systems, Aplication" and "Creative Design of Products and Systems". Saeed has also worked with a variety of companies, coalitions, and institutions. Ph.D., Mechanical Engineering, University of California, Davis, 1982. M.Sc., Mechanical Engineering (Design), Stanford University, 1976. B.Sc., Mechanical Engineering, Tehran Polytechnic, 1975. Registered Mechanical Engineer in State of California.

Frank Owen, California Polytechnic State University 


\title{
Design Education at Cal Poly: Why We Do What We Do
}

\begin{abstract}
Design education at Cal Poly starts in the freshman year and continues through the senior year. At the freshman level, we introduce students to design concepts through a 1-unit lab that includes dissection of different devices, experiments with microprocessors, as well as design and building of a device for a competition. The sophomore level course includes creative design, design process, human factors, aesthetics and styling, design factors and issues, intellectual property, liability, and economics of design. In this course students design and build both whimsical as well as consumer-related products and systems. The junior year design education includes traditional machine design courses, stress and fatigue analysis, design of machine components, and design labs. And finally, the senior year design education includes a thermo-sciences related course, as well as the capstone design course. The capstone design course was modified to its present 3-quarter long format in order to make it more effective, to afford students a chance to experience a complete design-build-test process, and to continue with our tradition of industrially sponsored projects.
\end{abstract}

The approach we have adopted for many years has been to train students in the creative design process earlier, even before they have learned stress analysis or mechanical design. In this manner, as they take their design engineering courses, they can incorporate creativity and other aspects of the design process in their projects.

\section{Introduction}

Cal Poly's tradition of learn-by-doing is decades old. Our programs, throughout the University, are known for their hands-on approach, lab-oriented education, and design projects. The Mechanical Engineering program is a leading proponent of this approach.

Our hands-on, learn-by-doing philosophy is implemented throughout our curriculum, from introductory classes to the graduate program. Most of our mid- and upper division classes have a lab associated with them. We also emphasize projects, whether design or analysis, in most classes, and we provide opportunities for students to engage in many extracurricular projects.

Recently, there was a series of discussions held on campus related to the differences between learn-by-doing and project-based learning. Most faculty involved in these discussions agreed that although these two philosophies share many attributes, and even though they are both very legitimate ways of approaching education, the learn-by-doing philosophy is more encompassing. For example, both pedagogies do involve projects; however, learn-by-doing can be accomplished in many ways other than just projects. For example, a laboratory experiment may or may not be a project. Playing in an orchestra is not a project, but involves learning by doing (the practice of what the individual will do 
in his or her profession). Therefore, Cal Poly has not changed the learn-by-doing philosophy.

First, a bit of history. In the past, our first-year introductory Mechanical Engineering course included both a lecture and a lab. More than anything, it was an introduction to the practice of Mechanical Engineering, fit for young students who may not have even known what an engineer does (Cal Poly requires that applicants declare a major. Therefore, all the admitted students come to us as M.E. students.) First year students in Mechanical Engineering were required to take the course. However, the (large number of) transfer students were not required to take this course but another, described later, that included design, creativity, and design factors. This two-track approach created a disparity between our freshman and transfer students. Although the subjects of creativity and design process were reviewed again in the capstone design course, these two groups of students had different levels of experience with the subjects. Recently, we changed this approach. The present-day introductory course is a 1-unit laboratory, practice-based course, followed by the sophomore-level, general design course, also described later, that everyone takes. Therefore, all students, whether freshman or transfer, take the same courses.

\section{Methodology}

An important aspect of this learn-by-doing approach is design. We incorporate design into most of our engineering courses, from freshman to senior capstone classes and even some of our graduate classes. Design opportunities are also provided through extracurricular activities. These activities include human-powered vehicles, hybrid cars, formula cars, super-mileage cars (our latest achieved close to 2000 miles per gallon), solar car, HVAC projects, a sustainable-house project, robotic projects, chainless bicycle project, and many more. All of these devices are designed and built by students in our machine shops on campus.

The design education spans many courses, including the freshman introductory Mechanical Engineering course (ME-134), the sophomore-level philosophy of design course (ME-234), the two traditional junior-level machine design courses (ME-328 and ME-329), a thermal-science design course (ME-440), and the senior capstone design course (ME-428, ME429, and ME-430). In fact, some instructors include design projects (such as popsicle-stick bridge design and egg-launching design projects) in their statics and dynamics classes. Consequently, our students are involved in design education throughout their tenure at Cal Poly. In the following sections, we will discuss these courses in detail.

ME 134, Introduction to Mechanical Engineering: In its present form, this course is a 1-unit laboratory course that includes dissection of mechanical products, microprocessor control of sensors and other devices, experiments with springs and computer programs, as well as three design projects. The dissected products include drill motors and a Briggs and Stratton 1-cylinder, 4-stroke, lawn mower engine. 
The design projects include the design of a structure, a "whimsical" machine, and a lawnmower racer. The first project may involve the design of bridge made from straws and tape that carries a certain load. In this project, students have to design and build the structure based on the information provided to them, and then test it. One common occurrence is that many students do not realize that the structure must be designed in three dimensions until they test it. They immediately go back and redesign the structure. The second project is usually related to making a machine that will perform a trivial task, but the main intention is creativity. Examples include a vehicle that will transport a ball up a flight of stairs while hanging on a cable, an egg drop, a ball thrower, and the like. In the third project, the lawn-mower racer, a lawn mower chassis is powered by a cordless drill motor while the student rides the racer. The design involves the calculation of the optimum speed ratio for a pair of pulleys and a belt that connect the drill motor to the drive shaft. Therefore, using the power output curve of the motor and acceleration, torque, and speed equations, students calculate the optimum ratio for their weight. Although these design projects are relatively simple, and in some cases they are not based on engineering calculations, they provide insight into the design process, problem solving, design consequences, and the relationship between a concept and reality.

ME-234, Philosophy of Design: This course covers creativity, design process (including the development of design specifications, introduction to Quality Function Deployment, idea generation and selection techniques, and iterations), and design factors and issues such as design communication, teamwork, visualization and imagination, aesthetics, liability, human factors and safety, quality, economics of design, sustainability, intellectual property, and many more.

This course is perhaps the most non-traditional aspect of our design education at Cal Poly, and until recently, there were no books available that covered the material in a cohesive fashion ${ }^{1}$. This course intentionally lacks equations, stress analysis, and numberbased decision making; instead, it emphasizes creativity, system approach, relationships between and among the different aspects of the elements of a product or system, consideration of the consequences of design decisions, and human interactions with the design. It requires students to draw, to design, to make decisions, to solve completely open-ended problems, and to create products and systems (One instructor last year required one drawing per day).

At least two major design projects are included in this class. The first one is a RubeGoldberg-type machine, where creativity is the most important part of the design criteria. Students design and build their machine and test it. Although the construction of the device, whether or not it functions properly, the weight, and other measures are used for grading, the majority of the grade comes from creativity of the design. The projects are constructed by students, either in our machine shop, the University Craft Center, or students' houses. We are fortunate in having a substantial machine shop with excellent technicians available to our students. They learn machining in a formal class in the freshman year, and subsequently, after taking a safety test, use the machine shop for their projects. The final project involves the design and planning of a product with social or commercial value. It must be something that does not already exist, at least not exactly 
the way students design it, and therefore, in most cases should be patentable (in the past, at least two patent applications have been filed when financial support was available). In most cases, the product is designed for household use, for people with disabilities, or for specific target audiences such as teachers, mountain-climbers, or campers. Ideas include hand-held sewing machine, a shrimp-peeler, multitude of devices for the disabled such as a one-handed buttoning device, an easy-to-install tire chain, and a shark repellent, pomegranate seeder, new bike lock, and new robots.

ME-328 Introduction to Machine Design: This is a typical machine design course, where stress analysis, fatigue analysis, fracture mechanics, and failure theories are discussed $^{2,3,4}$. The associated dry laboratory provides an opportunity to have students engage in both weekly assignments, as well as a final project. Students design a product such as a press, a saddle rack for horses, or similar objects. These design activities are meant to exercise the students' ability in machine component design. However, many instructors also include more system-oriented design projects in this course.

ME-329 Intermediate Design: This course involves the machine component design portion of traditional machine design books ${ }^{2,3,4}$, and includes bolts, welds, gears, springs, and other components. The projects presented in the associated dry lab relate to the design of machine components as they are used in a system. In one example, teams of students were assigned tasks that collectively related to the design of a helicopter. Each team was responsible for a portion of the total system, for example, the gear reduction, the flight mechanism, or the chassis, and had to coordinate its design with other teams. Other projects include the design of a Mars excavator made with parts from a Lego kit and a robotic rover.

ME-440 Thermal System Design: Although the senior capstone design class, described next, may include projects that involve thermal systems, this course is used to ensure that all students learn to design a thermal system. The course covers heat exchanger design and selection, piping systems and networks, thermal systems simulation, and analytical and computational optimization. It also includes engineering economics. In the associated dry lab, student teams are asked to design a thermal system and optimize it based on economic factors. Quarter-long projects include a ground-coupled heat pump system for buildings and a thermal energy storage system to be implemented on campus.

ME-428-429-430 Design series: This is our capstone design course. It has evolved very recently into a 3-quarter design sequence in which students design, build, and test a product or a system. Originally we offered a 1-quarter long, industry-supported, senior design course that involved the students in the analytical design of a product or system, plus a 2-quarter long individual senior project that was supervised by a faculty member. In order to offer a better and more uniform design experience for our students in a cohesive, team-based environment, these three quarters were combined into a 3-quarter design/build/test sequence, with the three quarters roughly divided amongst these three activities. 
Our faculty is very industry-oriented, with many having spent some part of their engineering career in industry. Therefore, all projects in this sequence are industry or industry-type projects. Because of our hands-on nature and our learn-by-doing philosophy, Cal Poly engineering graduates are known in the industries of the State of California as industry-ready upon graduation. This change in our design curriculum has enhanced our reputation even more. Industrial participants in our design sequence include Boeing, Solar Turbines, Parker Hannifin, the Golden Gate Bridge, the Deutsches Museum, Lockheed Martin, Raytheon, and a host of other companies. With the elimination of individual projects and the introduction of many industrial projects, the design sequence has developed a much more industry-like feel to it. The sequence has evolved even into a stepping stone from academic study to the working world. The sequence is much less "canned" than is a normal applied course-lab. Real-world situations and surprises arise constantly. So in running the course we have taken the attitude that this type of free structure is desirable because it very much mimics the working world. In managing the course we also often make decisions on whether or not the same would happen in the real world. If it does, and we have the industrial experience in our faculty to adjudge this, then we allow it, even if it would not normally be allowed in a conventional course. Often big changes in a project plan are accommodated because they make sense and would be allowed in the real world. Such big changes in a conventional course's curriculum hardly, if ever, occur. So in teaching a real world course like design, one must be willing to accept this open-ended structure in order to emulate the real world.

This course has all the common components of real-world design: project planning, tracking and management through Gantt charts, keeping logbooks, brainstorming, regular status meetings with agendas and minutes, and several presentations to present the design, manufacturing, and testing of the system. The sequence is managed by a team of professors who run the projects as engineering supervisors. It is in this class that students awaken to the fact that they are on the verge of their industrial careers and that the cozy comfort of academic life is coming to an end.

\section{Assessment}

We assess our program according to traditional, as well as ABET-inspired methods. Like everyone else, we use tests, project reports, design notebooks, and student presentations, both to the class and industry sponsors. For example, student teams make a formal presentation of their final projects in the Philosophy of Design course, the Thermal System Design course, as well as the senior project capstone design course. We also use poster sessions, where projects are presented to the class, the university community, as well as industry sponsors, who travel to the University to observe students' presentations. These poster sessions have become high profile events on campus, showcasing the realworld engineering skills of our mechanical engineering graduates. Often parents attend these events and are stunned by how fast their sons and daughters have been transformed into responsible engineers. 
We also assess our courses based on ABET requirements, and this includes surveys of our alumni, industry, graduating students, and faculty. It also includes the success rate of our graduating students in the Fundamentals of Engineering (FE) tests.

Perhaps the most important and direct measure of the success of our approach to the design education at Cal Poly is the success of our graduates. The industry seeks our graduates, and our graduates are very successful in their careers. They can hit the ground running on the first day of their employment, because they have done countless design projects, have been exposed to the design process and what it takes to imagine a solution, make decisions, find the answers, and implement and test them. The confirmation from the "product" of our program (the students) and the "customers" of our "products" (the industry) is the best witness of the appropriateness of this approach.

This is probably most clearly seen in the capstone design course, where the work with industry is very close. The pride students take in their final product or system is evident during the final design expo. The comments of students and the expo attendees are overwhelmingly positive. Parents are in awe and disbelief at the progress of their sons and daughters during their four or five short years at Cal Poly. Some industry sponsors initially believe that they are doing Cal Poly a favor by providing us a project. They too are often very surprised at the quality of our students' work, and subsequently, become regular participants in the program and bring increasingly sophisticated and significant projects for our students. Many have said that they value the students' fresh outlooks and attitudes that have not been influenced by their corporate culture. And, of course, sometimes a student will be hired by his or her corporate sponsor into a permanent position. There can be no measure of success better or more direct than that.

However, as is reported in our ABET self-study report ${ }^{5}$, many statistical measures are also used to gauge our students' success. For example, about $50 \%$ of our students take the FE exam while at school. The $1^{\text {st }}$-time passing rate is close to $98 \%$. We also use data collected by Cal Poly's Career Canter ${ }^{6}$ about employment opportunities and job offers. For example, the 2006-2007 survey of graduates showed that out of 83 respondents, 67 $(81 \%)$ were employed, $9(11 \%)$ were in graduate school, and $7(8 \%)$ were looking for employment or not seeking a job. The 2007-2008 survey showed that out of 102 respondents, $97(95 \%)$ of the graduates were employed and $2(2 \%)$ were in graduate school. Obviously, the success of our graduates is not only due to the courses mentioned above, but is the result of the caliber of the student body, the University climate, the opportunities provided to the students, the faculty of Cal Poly, as well as current economic and social conditions.

\section{References}

1. Niku, Saeed B., Creative Design of Products and Systems, John Wiley and Sons, 2009.

2. Budynas, Richard, and K. Nisbett, Mechanical Engineering Design, Mc Graw-Hill, 2006.

3. Juvinall, Robert, and K. M. Marshek, Fundamentals of Machine Component Design, John Wiley and Sons, 2005.

4. Norton, Robert L., Machine Design: An Integrated Approach, Prentice-Hall, 2005. 
5. https://blackboard.calpoly.edu/webapps/portal/frameset.jsp?useCas=1\&tab=courses\&url=/bin/com mon/course.pl?course_id=_132613

6. http://careers.calpoly.edu/search_2007.php. 